importance of surveillance at points of entry to mitigate the risk for ASFV introduction through illegal imports.

\section{Acknowledgments}

The authors thank staff from the Pirbright Institute for providing the ASFV OURT88/3 strain.

This project was supported financially by a grant (no. B-1543085-2017-18-02) from the Animal and Plant Quarantine Agency, the Ministry of Agriculture, Food and Rural Affairs, South Korea.

\section{About the Author}

Dr. Kim is a veterinary researcher working for the Foreign Animal Disease Research Division, Animal and Plant Quarantine Agency, Gimcheon, South Korea. Her research interests are diagnostics and the prevention of disease in animals from emerging pathogens.

\section{References}

1. Zhou X, Li N, Luo Y, Liu Y, Miao F, Chen T, et al. Emergence of African swine fever in China, 2018. Transbound Emerg Dis. 2018;65:1482-4. http://dx.doi.org/10.1111/tbed.12989

2. Ge S, Li J, Fan X, Liu F, Li L, Wang Q, et al. Molecular characterization of African swine fever virus, China, 2018. Emerg Infect Dis. 2018;24:2131-3. http://dx.doi.org/10.3201/ eid2411.181274

3. Kolbasov D, Titov I, Tsybanov S, Gogin A, Malogolovkin A. African swine fever virus, Siberia, Russia, 2017. Emerg Infect Dis. 2018;24:796-8. http://dx.doi.org/10.3201/eid2404.171238

4. World Organisation for Animal Health. African swine fever. In: Manual of diagnostic tests and vaccines for terrestrial animals. Paris: The Organisation; 2012.

5. Bastos ADS, Penrith ML, Crucière C, Edrich JL, Hutchings G, Roger F, et al. Genotyping field strains of African swine fever virus by partial $p 72$ gene characterisation. Arch Virol. 2003;148:693-706. http://dx.doi.org/10.1007/s00705-002-0946-8

6. Gallardo C, Fernández-Pinero J, Pelayo V, Gazaev I, Markowska-Daniel I, Pridotkas G, et al. Genetic variation among African swine fever genotype II viruses, eastern and central Europe. Emerg Infect Dis. 2014;20:1544-7. http://dx.doi. org/10.3201/eid2009.140554

7. Gallardo C, Mwaengo DM, Macharia JM, Arias M, Taracha EA, Soler A, et al. Enhanced discrimination of African swine fever virus isolates through nucleotide sequencing of the $p 54, p 72$, and $p B 602 L$ (CVR) genes. Virus Genes. 2009;38:85-95. http://dx.doi.org/10.1007/s11262-008-0293-2

8. Food and Agriculture Organization of the United Nations. African swine fever threatens People's Republic of China: a rapid risk assessment of ASF introduction. Animal health risk analysis. Assessment no. 05. 2018 Mar 6 [cited 2018 Oct 31]. http://www.fao.org/3/i8805en/I8805EN.pdf

9. Li X, Tian K. African swine fever in China. Vet Rec. 2018; 183:300-1. http://dx.doi.org/10.1136/vr.k3774

10. Penrith ML, Vosloo W. Review of African swine fever: transmission, spread and control. J S Afr Vet Assoc. 2009;80:5862. http://dx.doi.org/10.4102/jsava.v80i2.172

Address for correspondence: Hyang-Mi Nam, Animal and Plant Quarantine Agency, 177, Hyeoksin 8-ro Gimcheon 39660, South Korea; email: namhm@korea.kr

\title{
Hepatitis E Virus Infection in European Brown Hares, Germany, 2007-2014
}

\section{Victor Max Corman, Laura Hilgensloh, Ulrich Voigt, Marco Marklewitz, Ursula Siebert, Christian Drosten, Jan Felix Drexler}

Author affiliations: Charité-Universitätsmedizin Berlin, Berlin, Germany (V.M. Corman, M. Marklewitz, C. Drosten, J.F. Drexler); German Centre for Infection Research (DZIF), Berlin (V.M. Corman, C. Drosten, J.F. Drexler); University of Bonn Medical Centre, Bonn, Germany (L. Hilgensloh); University of Veterinary Medicine Hannover Foundation, Hannover, Germany (U. Voigt, U. Siebert)

DOI: https://doi.org/10.3201/eid2506.181618

Rabbit-associated hepatitis E viruses (HEVs) cause zoonotic infections. We investigated 2,389 hares in Germany during 2007-2014. Complete genome characterization of a hare-associated HEV strain revealed close genomic relatedness to rabbit-associated HEV strains. Although harespecific HEV seroprevalence was low, at $2.6 \%$, hares represent a potential source of sporadic HEV infections.

$\mathrm{H}$ epatitis E virus (HEV; family Hepeviridae, genus Orthohepevirus) is a major cause of acute hepatitis in humans worldwide. Large outbreaks have included waterborne $\mathrm{HEV}$ in the tropics and zoonotic infections in temperate climates (1). In 2017, researchers identified human infection with HEV strains associated with rabbits (raHEV) in France (2,3).

In Germany, rabbits (family Leporidae, genus Oryctolagus) are common in the wild but are also popular pets, potentially explaining human exposure to raHEV. Hares (family Leporidae, genus Lepus), although genetically related, are physically larger and are primarily hunted as food in large parts of Europe ( $>5$ million hares annually) (4). HEV associated with hares (haHEV) had been previously unknown (5). For this study, we tested for HEV in 2,389 European brown hares (L. europaeus) hunted in Germany during 2007-2014, across an area of $\approx 30,000 \mathrm{~km}^{2}$ (Appendix Figure 1, http://wwwnc.cdc.gov/ EID/article/25/6/18-1618-App1.pdf). One animal (0.04\% of all samples; $95 \%$ CI $0.03 \%-0.05 \%$ ) tested positive in a broadly reactive reverse transcription PCR assay; $25(2.6 \%$; 95\% CI $1.6 \%-3.5 \%)$ animals were identified as seropositive.

RNA concentration was $5.4 \times 10^{4} \mathrm{IU} / \mathrm{mL}$ in the serum of the animal that tested positive, comparable to viral loads observed in rabbits and in human blood donors $(3,6)$. After we determined its complete viral genome (GenBank accession 
no. MK050463), the haHEV isolate showed the typical genome organization of Orthohepevirus A, including 3 predicted open reading frames (ORF). We found a 93-nt insertion in the X-domain of ORF1 that is thought to be typical of raHEV strains and absent in other HEV strains $(2,3)$. This finding may reflect a common origin of raHEV and haHEV strains or a host-associated virus adaptation. We found no evidence for recombination of haHEV with other Orthohepevirus species or subtypes.

When averaged over the complete genome, the haHEV isolate we obtained shared $86 \%$ nucleotide identity with the most closely related raHEV strain (GenBank accession no. KY436898), from a rabbit sampled in Germany in 2016 (5). Average translated amino acid identity of the haHEV with raHEV strains was high at $88.5 \%-97.5 \%$ for ORF $1,90.2 \%-98.5 \%$ for ORF2, and $88.6 \%-95.1 \%$ for ORF3. In phylogenetic reconstructions, the haHEV clustered with raHEV strains, further suggesting a common origin for haHEV and raHEV, and suggesting an origin of haHEV in ancestors carried by rabbits and distinct from the greater HEV diversity existing in swine (7) (Figure; Appendix Figure 2). This interpretation is consistent with sporadic sharing of habitats between wild rabbits and hares in the study area.
To determine seroprevalence, we expressed the capsid protein of haHEV and used it for indirect immunofluorescence assays (Appendix). In total, serum samples from 944 hares, covering all sampling regions and years, were available in sufficient quality and quantity for serological testing (Appendix Table 2). HEV seroprevalence for hares was $2.6 \%$ (95\% CI 1.6\%-3.5\%), similar to values in a previous serologic study of 669 European brown hares that used a capsid fragment from a human HEV genotype 1 strain as antigen and yielded a seroprevalence of $1.6 \%-4.3 \%$ (5). The sampling sites from that study were up to $400 \mathrm{~km}$ from those in our study, suggesting geographically widespread HEV infection of hares. That study also found wild rabbits to be seropositive at rates $>35 \%$ (5). The lower HEV seroprevalence in hares than in rabbits might be explained by the fact that hares live solitarily and have low-density populations, $\approx 12-20$ animals/100 ha in the sampling region; wild rabbits live in groups of $\approx 15$ that are also proximal to other groups.

We found no statistically significant differences in seroprevalence for hares $<1$ versus $>1$ year of age $\left(\chi^{2} 0.08 ; p\right.$ $=0.78)$, which is unlike the age-dependent increase of seropositivity observed in pigs and humans $(8,9)$. Explanations may include a lack of statistical power in this study or differential pathogenesis of HEV in hares. Although the data

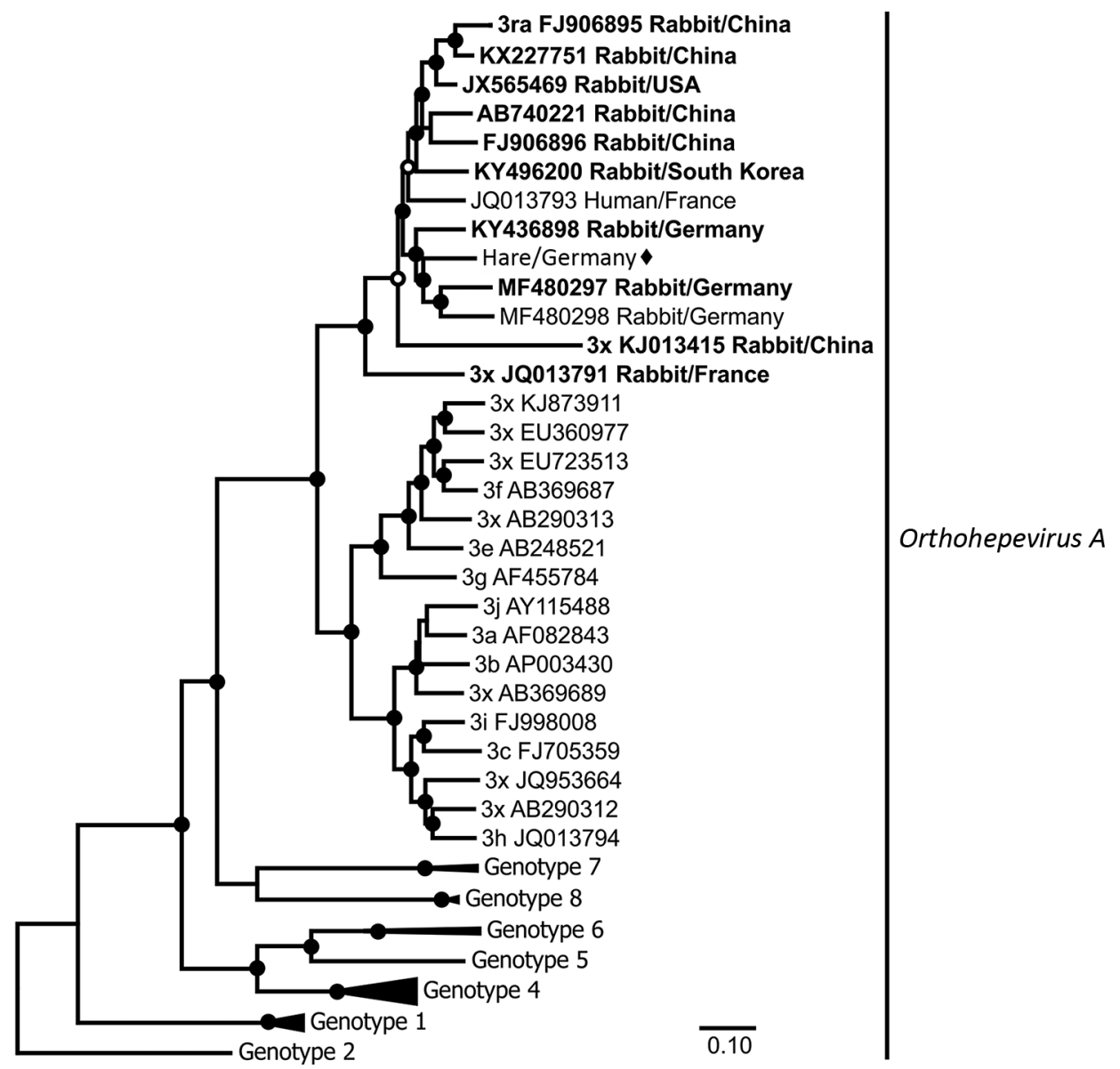

Figure. Maximum-likelihood phylogeny of the concatenated open reading frame 1 and 2 nucleotide sequences of hare hepatitis $\mathrm{E}$ virus (HEV) strain from Germany (black diamond), related strains from rabbits (bold) and humans, and reference Orthohepevirus A strains, as defined by Smith et al. (7). Taxon names of all reference sequences include genotype, subtype ( $\mathrm{x}$ if not available), and GenBank accession number. Black circles at nodes indicate bootstrap supports of $>90 \%$ and white circles $>75 \%$ (1,000 replicates). The clades comprising sequences other than HEV genotype 3 were collapsed for graphical reasons. Scale bar indicates nucleotide substitutions per site. 
on HEV pathogenesis in rabbits are in part controversial, occurrence of HEV in apparently healthy laboratory rabbits suggests that rabbits frequently survive HEV infection (10). Whether the apparently low seroprevalence in hares compared with rabbits is thus due to infrequent infection, differential antibody responses, or other host- or virus-associated factors remains to determined.

We detected no statistically significant differences in seroprevalence rates, either between sexes $\left(\chi^{2} 0.01 ; p\right.$ $=0.92$ ) or across the 8 sampling years (Yates $\chi^{2} 0.6 ; p$ $=0.96$ ) and the 5 individual sampling regions (Yates $\chi^{2}$ $1.945 ; p=0.96)$. These findings suggested constant low levels of HEV transmission in hares irrespective of sex and geographic region.

The infection of hares with HEV strains that are closely related to raHEV strains suggests that hares may act as sporadic sources of zoonotic HEV infections. Although the low RNA detection rate and seroprevalence speak against a prominent role of hares in the epidemiology of zoonotic $\mathrm{HEV}$, hunters and persons handling hare-derived products could represent risk groups. Awareness about hare-derived HEV infections may be particularly relevant for immunocompromised persons, in whom chronic HEV infections are most common.

\section{Acknowledgments}

We thank all hunters for their help during fieldwork, Joerg Roesner for help with immunofluorescence microscopy, and Sarah Schulz for providing HEV antibody reference material.

This research was supported by a grant from the German Federal Ministry of Health (grant ZMVI1-2518FSB705) to V.M.C.

\section{About the Author}

Dr. Corman is a physician and virologist at the Institute of Virology, Charité-Universitätsmedizin Berlin. His current research is dedicated to characterization of novel human and zoonotic viruses and development of diagnostic tools.

\section{References}

1. Aggarwal R. The global prevalence of hepatitis E virus infection and susceptibility: a systematic review. Geneva: World Health Organization; 2010.

2. Abravanel F, Lhomme S, El Costa H, Schvartz B, Peron JM, Kamar N, et al. Rabbit hepatitis E virus infections in humans, France. Emerg Infect Dis. 2017;23:1191-3. http://dx.doi.org/ 10.3201/eid2307.170318

3. Izopet J, Dubois M, Bertagnoli S, Lhomme S, Marchandeau S, Boucher $\mathrm{S}$, et al. Hepatitis E virus strains in rabbits and evidence of a closely related strain in humans, France. Emerg Infect Dis. 2012;18:1274-81. http://dx.doi.org/10.3201/eid1808.120057

4. Chapman JA, Flux JEC; International Union for Conservation of Nature and Natural Resources. Lagomorph Specialist Group. Rabbits, hares, and pikas: status survey and conservation action plan. Gland (Switzerland): International Union for Conservation of Nature and Natural Resources; 1990.
5. Hammerschmidt F, Schwaiger K, Dähnert L, Vina-Rodriguez A, Höper D, Gareis M, et al. Hepatitis E virus in wild rabbits and European brown hares in Germany. Zoonoses Public Health. 2017;64:612-22. http://dx.doi.org/10.1111/zph.12355

6. Hewitt PE, Ijaz S, Brailsford SR, Brett R, Dicks S, Haywood B, et al. Hepatitis $\mathrm{E}$ virus in blood components: a prevalence and transmission study in southeast England. Lancet. 2014;384: 1766-73. http://dx.doi.org/10.1016/S0140-6736(14)61034-5

7. Smith DB, Simmonds P, Izopet J, Oliveira-Filho EF, Ulrich RG, Johne R, et al. Proposed reference sequences for hepatitis E virus subtypes. J Gen Virol. 2016;97:537-42. http://dx.doi.org/10.1099/ jgv.0.000393

8. Krumbholz A, Joel S, Neubert A, Dremsek P, Dürrwald R, Johne R, et al. Age-related and regional differences in the prevalence of hepatitis E virus-specific antibodies in pigs in Germany. Vet Microbiol. 2013;167:394 402. http://dx.doi.org/10.1016/j.vetmic.2013.10.001

9. Faber MS, Wenzel JJ, Jilg W, Thamm M, Höhle M, Stark K. Hepatitis E virus seroprevalence among adults, Germany. Emerg Infect Dis. 2012;18:1654-7. http://dx.doi.org/10.3201/eid1810.111756

10. Han SH, Park BJ, Ahn HS, Kim YH, Go HJ, Kim DH, et al. Evidence of hepatitis $\mathrm{E}$ virus infection in specific pathogen-free rabbits in Korea. Virus Genes. 2018;54:587-90. http://dx.doi.org/ $10.1007 / \mathrm{s} 11262-018-1562-3$

Address for correspondence: Victor Max Corman, Institute of Virology, Charité-Universitätsmedizin Berlin, 10117 Berlin, Germany, email: victor.corman@charite.de

\section{Sarcoptic Mange of Fox Origin in Multiple Farm Animals and Scabies in Humans, Switzerland, 2018}

\author{
Simone R.R. Pisano, Marie-Pierre Ryser-Degiorgis, \\ Luca Rossi, Andrea Peano, Karin Keckeis, \\ Petra Roosje
}

Author affiliations: University of Bern, Bern, Switzerland

(S.R.R. Pisano, M.-P. Ryser-Degiorgis, P. Roosje); University

of Turin, Grugliasco, Italy (L. Rossi, A. Peano); consulting

veterinarian, Wabern, Switzerland (K. Keckeis)

DOI: https://doi.org/10.3201/eid2506.181891

Fox-derived Sarcoptes scabiei mites caused an outbreak of mange on a farm in Switzerland in 2018. Pruritic skin lesions suggestive of $S$. scabiei mite infestation developed in 4 humans who had direct contact with affected farm animals but not foxes. Sarcoptic mange is continuously spreading; such outbreaks affecting humans could start occurring more frequently. 